\title{
Examination of social determinants of health among patients with limited English proficiency
}

\author{
Austin Fischer ${ }^{1}$, Joseph Conigliaro ${ }^{1,2}$, Shaun Allicock ${ }^{1,3}$ and Eun Ji Kim ${ }^{1,2^{*}}$ (D)
}

\begin{abstract}
Objectives: The purpose of this study is to examine the prevalence of social needs by English proficiency using data from Northwell Health's social determinants of health screening program. The screening program evaluates 12 domains of social needs: material need, employment, medical-legal assistance, health insurance, public benefits, health literacy, transportation, medical care, utilities, housing quality, food security, and housing insecurity. We have identified patients to have limited English proficiency if they have selected a language other than English as their primary language.

Results: The study population includes 92,958 individuals; of these, 83,445 (89.8\%) patients are English proficient, and 9513 (10.2\%) patients have limited English proficiency. A higher percentage of patients with limited English proficiency has social needs, including material need, employment, medical-legal assistance, health insurance, public benefit, health literacy, medical care, utility bill, poor housing quality, and food insecurity (all p-values $<0.05$ ). In multivariable logistic regression models adjusting for sociodemographic information, LEP status (odds ratio $=1.36$ [1.25-1.49]) has been associated with having social needs. These findings suggest that system-wide SDH screening and referral programs should identify ways to ensure capturing social needs among patients with limited English proficiency.
\end{abstract}

Keywords: Social determinants of health, Limited English proficiency, Health disparities, Population health

\section{Introduction}

Increasingly, the implications of social determinants of health (SDH) stretch beyond the individual, with the excess medical cost of inequalities estimated at $\$ 93$ billion annually $[1,2]$. Recent efforts have focused on systematically documenting $\mathrm{SDH}$, particularly unmet social needs, as these factors have been shown to play a larger role in the health of an individual than either insurance status or access to care [3]. While the ultimate goal is to address systemic inequalities, evaluating population-level data offers the capacity for tailored intervention for vulnerable patients [4].

\footnotetext{
*Correspondence: ekim7@northwell.edu

${ }^{1}$ Department of Medicine, Donald and Barbara Zucker School

of Medicine at Hofstra/Northwell, 500 Hofstra Blvd, Hempstead, NY 11549,

USA

Full list of author information is available at the end of the article
}

Limited English proficiency (LEP) has been established as a risk factor for poorer access to care, decreased healthcare utilization, and adverse health outcomes [5]. There is a need to understand the conditions impacting LEP patients, as this cohort has grown rapidly and now represents more than 25 million Americans [6]. This is particularly true in communities that have limited expertise, capital, and infrastructure to promote equity for this group. Despite past work investigating health outcome disparities in LEP patients, less is known about the presence of social needs in patients with LEP.

To fill this gap, using data from an integrated health network, we examined the presence of social needs by LEP status. In particular, we sought to evaluate the presence of social needs among patients with Spanish as a primary language. As the LEP population grows and expands to areas ill-equipped to support this group, 
understanding the prevalence of these individual needs will be key to addressing the social factors that ultimately impact their health.

\section{Main text \\ Methods \\ Study population}

The SDH screening program has been implemented in an inpatient setting at 11 acute-care hospitals throughout the Northwell Health system. The goal of the screening program is to estimate SDH risk by detecting both individual and community-level SDH prevalence. These hospitals are located throughout the New York City area and encompass a diverse population, including racial/ethnic minorities, immigrants, and traditionally underserved populations.

Our data consisted of SDH screenings conducted from June 25th, 2019 through February 29th, 2020. The SDH screening tool is embedded within nursing notes; upon admission, nurses complete the SDH screening along with patients' demographic, clinical, and insurance information.

We included all adults (aged 18 years or older) that responded to the screening. For patients with multiple hospitalizations, we included their first hospitalization to prevent over-representation. We excluded patients with missing demographic information or preferred primary language.

\section{Outcome measures}

Our primary outcome measure was the presence of social needs. The SDH screening tool evaluates 12 areas of social needs, including material need, employment, medical-legal assistance, health insurance, public benefits, health literacy, transportation, medical care, utilities, housing quality, food security, and housing insecurity (Additional file 1: Table S1). Each response is documented as "yes" or "no".

\section{Independent variables}

Our primary independent variable was LEP: patients who selected a language other than English as their primary language were categorized as LEP and those who preferred English as their primary language were categorized as non-LEP. Furthermore, patients with LEP were subcategorized into two cohorts: Spanish primary language and non-Spanish primary language. We also identified key demographic variables associated with the presence of social needs, including age, gender, race/ethnicity, and insurance. Responses for race/ethnicity were organized into White non-Hispanic, Black non-Hispanic, Hispanic, Asian, Native American/Alaskan, other/multiracial, and unknown/declined. Furthermore, health insurance responses were categorized into commercial, Medicare, Medicaid, self-pay, and unknown.

\section{Statistical analyses}

We performed a descriptive analysis of all participants, and then by English proficiency status. We calculated the mean and standard deviation for continuous variables and the percentage for categorical variables. Finally, to examine differences by English proficiency status, we calculated t-tests for continuous variables and chi-squared tests for categorical variables. We first compared English proficiency versus LEP, and then we further examined Spanish as a primary language because Spanish is the most common non-English language spoken in the United States. Lastly, we ran multivariable logistic regression models to examine patient characteristics associated with having at least one social need, including LEP status. Statistical analyses were conducted using SAS software (SAS Institute Inc., Cary NC, USA).

\section{Results \\ Population characteristic}

The study population included 92,958 individuals who had responses to SDH screenings; of these, 83,445 (89.8\%) patients were English proficient and 9513 (10.2\%) patients had LEP (Fig. 1). There were differences in sociodemographic characteristics, including age, gender, race/ethnicity, and health insurance, between patients who are English proficient versus LEP (Table 1). A higher percentage of patients with LEP were Hispanic (40.8\% versus $8.7 \%$, $\mathrm{p}$-value $<0.001)$ and had Medicaid $(26.8 \%$ versus $10.4 \%$, $\mathrm{p}$-value $<0.001)$ compared to patients with English proficiency.

\section{Social needs}

Presence of social needs were: $0.5 \%$ material need, $0.7 \%$ employment, $0.4 \%$ medical-legal assistance, $1.7 \%$ health insurance, $1.8 \%$ public benefits, $1.2 \%$ health literacy, $1.5 \%$ transportation, $0.9 \%$ medical care, $2.1 \%$ utilities, $0.7 \%$ housing quality, $1.1 \%$ food security, and $1.3 \%$ housing insecurity. There also were differences in the presence of social needs based on LEP status (Table 1). A higher percentage of patients with LEP had social needs, including material need, employment, medical-legal assistance, health insurance, public benefit, health literacy, medical care, utility bill, poor housing quality, and food insecurity (all p-values $<0.05$ ). Then we examined the presence of social needs among English proficient, Spanish primary language, and non-Spanish primary language; higher percentages of patients with Spanish as a primary language had social needs compared to patients with English proficiency (all p-values $<0.001$ ). For example, $1.1 \%$ of patients 


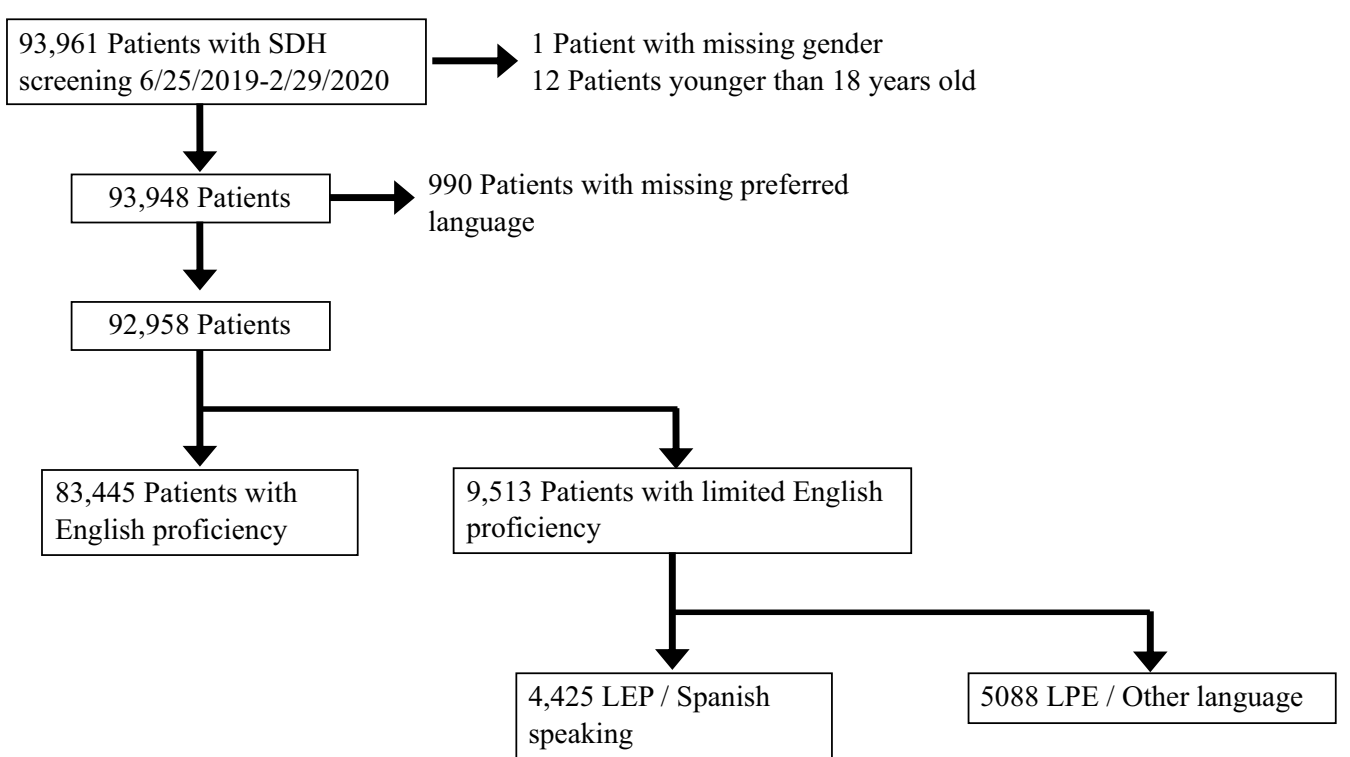

Fig. 1 Flowchart of study population

with English proficiency versus $1.5 \%$ of patients with LEP and $2.6 \%$ of patients with Spanish as a primary language had food insecurity ( $\mathrm{p}$-value $<0.001$ ).

\section{Multivariable logistic regressions}

We then examined patient characteristics associated with having at least one social need (Table 2). In the base model, racial minorities, except Asians (odds ratio $(\mathrm{OR})=0.86[95 \%$ confidence interval $=0.76-0.98])$, had increased odds of having social need(s) compared to nonHispanic Whites. Being male $(\mathrm{OR}=1.23[1.17-1.30])$ and having Medicare or Medicaid $(\mathrm{OR}=2.17$ [2.03-2.32]) were also associated with having social needs. When we included LEP status into the base model, LEP was associated with increased odds $(\mathrm{OR}=1.36$ [1.25-1.49]) of having social needs. When we further examined LEP status by Spanish speaking or not, Spanish as a primary language was associated with increased odds $(\mathrm{OR}=1.74$ [1.55-1.95]), and non-Spanish was not associated $(\mathrm{OR}=1.02[0.89-1.17])$ with having social needs.

\section{Discussion}

Using data from a large integrated health system, this study illustrated that LEP status was associated with an increased presence of social needs, including material need, employment, medical-legal assistance, health insurance, public benefit, health literacy, medical care, utility bill, poor housing quality, and food insecurity. Additionally, patients with Spanish as a primary language had increased social needs across all domains, including public transportation and housing insecurity. This finding persisted even after adjusting for covariates in multivariable logistic regression analysis. As SDH screening is expanding at hospitals and health systems, it will be vital to capture social needs among LEP patients. Ultimately, these data can be utilized to understand the root causes of these health disparities-the identification of social needs associated with healthcare utilization and health outcomes [7]. Furthermore, hospitals and health systems can allot existing limited resources to improve patients' health outcomes.

Predictably, the root of LEP disparities centers on language. Language barriers are known to perpetuate cultural barriers, as limited understanding of American culture can prevent the assimilation of immigrants and refugees. In turn, the combination of lingual and cultural barriers restricts LEP individuals from accessing and utilizing medical care and connecting to community resources $[5,8]$. Despite the recognition of these phenomena, the responsibility of resolving disparities in LEP has by and large fell onto the patient. While the identification of subgroups most vulnerable to adverse outcomes is key to guiding focused intervention, what is needed now is a thorough understanding of the interventions to address social needs among patients with LEP.

In clinical settings, interventions to address social needs have centered on recruiting assistance from nonprofits, expanding culturally competent practices, and increasing patient engagement [9-12]. Efforts from the voluntary sectors have been particularly useful, as these organizations are positioned to be the bridge between the clinic and resources necessary to address social needs. 
Table 1 Patient characteristics by English proficiency, n (\%) for categorical variables and mean (standard deviation) for continuous variables

\begin{tabular}{|c|c|c|c|c|}
\hline & \multirow[t]{2}{*}{ All $(n=92,958)$} & \multirow{2}{*}{$\begin{array}{l}\text { English proficient } \\
(n=83,445)\end{array}$} & \multicolumn{2}{|c|}{ Limited English proficiency } \\
\hline & & & All $(n=9513)^{a}$ & Spanish $(n=4425)^{b}$ \\
\hline Age, years & $65.2(18.3)$ & $64.8(18.3)$ & $69.0(17.2)$ & $63.8(18.9)$ \\
\hline \multicolumn{5}{|l|}{ Gender } \\
\hline Female & $49,211(52.9 \%)$ & $43,767(52.5 \%)$ & $5444(57.2 \%)$ & $2544(57.5 \%)$ \\
\hline Male & $43,747(47.1 \%)$ & $39,678(47.6 \%)$ & $4069(42.8 \%)$ & $1881(42.5 \%)$ \\
\hline \multicolumn{5}{|l|}{ Race/ethnicity } \\
\hline White, non-Hispanic & $50,692(54.5 \%)$ & $48,917(58.6 \%)$ & 1775 (18.7\%) & $122(2.8 \%)$ \\
\hline Black, non-Hispanic & $15,130(16.3 \%)$ & $14,753(17.7 \%)$ & $377(4.0 \%)$ & $14(0.3 \%)$ \\
\hline Hispanic & $11,156(12.0 \%)$ & $7274(8.7 \%)$ & $3882(40.8 \%)$ & $3838(86.7 \%)$ \\
\hline Asian & $6327(6.8 \%)$ & $4428(5.3 \%)$ & $1899(20.0 \%)$ & $6(0.1 \%)$ \\
\hline Native American/Alaskan & $477(0.5 \%)$ & $368(0, .4 \%)$ & $109(1.2 \%)$ & $2(0.05 \%)$ \\
\hline Other/multiracial & $6494(7.0 \%)$ & $5392(6.5 \%)$ & $1102(11.6 \%)$ & $355(8.0 \%)$ \\
\hline Unknown/decline & $2682(2.9 \%)$ & $2313(2.8 \%)$ & $369(3.9 \%)$ & $88(2.0 \%)$ \\
\hline \multicolumn{5}{|l|}{ Health insurance } \\
\hline Commercial & $29,065(31.3 \%)$ & $27,533(33.0 \%)$ & $1532(16.1 \%)$ & $931(21.0 \%)$ \\
\hline Medicare & $36,176(38.9 \%)$ & $32,194(38.6 \%)$ & $3982(41.9 \%)$ & $1649(37.3 \%)$ \\
\hline Medicaid & $11,215(12.1 \%)$ & 8665 (10.4\%) & $2550(26.8 \%)$ & $1334(30.2 \%)$ \\
\hline Self-pay & $735(0.8 \%)$ & $588(0.7 \%)$ & $147(1.6 \%)$ & $112(2.5 \%)$ \\
\hline Unknown & $15,767(17.0 \%)$ & $14,465(17.3 \%)$ & $1302(13.7 \%)$ & $399(9.0 \%)$ \\
\hline \multicolumn{5}{|l|}{ Patient-reported social needs } \\
\hline Material need & 459/92,842 (0.5\%) & $391 / 83,348(0.5 \%)$ & $68 / 9494(0.7 \%)$ & $49 / 4417(1.1 \%)$ \\
\hline Employment & $623 / 92,781(0.7 \%)$ & $528 / 83,291(0.6 \%)$ & $95 / 9490(1.0 \%)$ & $88 / 4414(2.0 \%)$ \\
\hline Medical legal assistance & $390 / 92,764(0.4 \%)$ & $325 / 83,281(0.4 \%)$ & $65 / 9483(0.7 \%)$ & $53 / 4414(1.2 \%)$ \\
\hline Health insurance & 1587/91,188 (1.7\%) & $1262 / 83,285(1.5 \%)$ & $325 / 9490(3.4 \%)$ & $246 / 4417(5.6 \%)$ \\
\hline Public benefit & $1630 / 92,806(1.8 \%)$ & $1391 / 83,312(1.7 \%)$ & $239 / 9494(2.5 \%)$ & $169 / 4416(3.8 \%)$ \\
\hline Health literacy & $1122 / 92,769(1.2 \%)$ & $765 / 83,284(0.9 \%)$ & $357 / 9485(3.8 \%)$ & 220/4415 (5.0\%) \\
\hline Public transportation & $1382 / 92,782(1.5 \%)$ & $1225 / 83,291(1.5 \%)$ & 157/9491 (1.7\%) & $110 / 4413(2.5 \%)$ \\
\hline Medical care & $788 / 92,784(0.9 \%)$ & $687 / 83,292(0.8 \%)$ & 101/9492 (1.1\%) & $80 / 4415(1.8 \%)$ \\
\hline Utility bill & 1939/92,797 (2.1\%) & $1709 / 83,304(2.1 \%)$ & 230/9493 (2.4\%) & $182 / 4416(4.1 \%)$ \\
\hline Poor housing quality & $628 / 92,872(0.7 \%)$ & $588 / 83,370(0.7 \%)$ & 40/9502 (0.4\%) & $30 / 4420(0.7 \%)$ \\
\hline Food insecurity & $1018 / 92,850(1.1 \%)$ & 879/83,354 (1.1\%) & $139 / 9496(1.5 \%)$ & $114 / 4417(2.6 \%)$ \\
\hline Housing insecurity & $1205 / 92,902(1.3 \%)$ & $1080 / 83,395(1.3 \%)$ & $125 / 9507(1.3 \%)$ & $100 / 4423(2.3 \%)$ \\
\hline
\end{tabular}

${ }^{a}$ Chi-square test of similarity comparing patients with English proficiency versus patients with limited English proficiency were all less than 0.001 , except public transportation and housing insecurity

${ }^{b}$ Chi-square test of similarity comparing Spanish speaking patients versus non-Spanish speaking patients were all less than 0.001

For example, the NOWPOW program links together a patient's electronic health record with community-based databases to generate prescriptions for patients in need $[10,13]$. Also, there is great utility in expanding culturally competent practices, such as the use of interpreters and providing language-appropriate materials. Despite an extensive amount of literature demonstrating the efficacy of trained interpreters in improving health outcomes, reducing healthcare costs, and increasing health literacy, patients with LEP are frequently communicated without an interpreter [14]. Furthermore, patient engagement has been cited as a method for addressing healthcare disparities, but has failed to incorporate populations likely to experience disparities onto patient/family advisory groups. Therefore, the path to addressing social needs within the LEP population will be an interdisciplinary approach, paved through combined local and federal intervention.

\section{Conclusion}

Both LEP status and Spanish as a primary language were associated with an increased presence of social needs. While legislation exists to ensure care equality, gaps in implementation place the responsibility on 
Table 2 Patient characteristics associated with having at least one social need (odds ratio [95\% confidence interval])

\begin{tabular}{llcl}
\hline & Base model & Base model+LEP & $\begin{array}{c}\text { Base } \\
\text { model+LEP } \\
\text { (Spanish) }\end{array}$ \\
\hline Race/ethnicity (reference: non-Hispanic White) & & & $1.81[1.68-1.94]$ \\
Black & $1.81[1.68-1.94]$ & $1.81[1.68-1.94]$ & $1.47[1.34-1.62]$ \\
Hispanic & $1.83[1.70-1.98]$ & $1.64[1.51-1.79]$ & $0.86[0.76-0.98]$ \\
Asian & $0.86[0.76-0.98]$ & $0.79[0.70-0.90]$ & $1.32[1.19-1.46]$ \\
Other & $1.38[1.24-1.52]$ & $1.31[1.18-1.45]$ & $1.77[1.54-2.03]$ \\
Unknown/decline & $1.82[1.59-2.08]$ & $1.75[1.52-2.00]$ & $0.98[0.98-0.98]$ \\
Age & $0.98[0.98-0.99]$ & $0.98[0.98-0.98]$ & $1.24[1.18-1.31]$ \\
Male & $1.23[1.17-1.30]$ & $1.24[1.18-1.31]$ & $2.14[2.00-2.29]$ \\
Health insurance (reference: commercial health insurance) & & $1.06[0.65-1.16]$ \\
Medicare/Medicaid & $2.17[2.03-2.32]$ & $2.14[2.00-2.29]$ & $1.05[0.95-1.15]$ \\
No health insurance/unknown & $1.05[0.96-1.16]$ & & $1.36[1.25-1.49]$ \\
LEP (reference: English speaking) & & & $1.74[1.55-1.95]$ \\
LEP & & & $1.02[0.89-1.17]$ \\
Spanish speaking & & & \\
Non-Spanish LEP & & & \\
\hline
\end{tabular}

providers, hospital systems, and communities to be forerunners in screening and addressing social needs. Accurately capturing social needs among patients with LEP to ensure subsequent referral to appropriate services is paramount. Additionally, research is needed investigating the presence of underreporting in $\mathrm{SDH}$ screenings of LEP populations, as well as exploring the efficacy of interventions.

\section{Limitation}

There are several study limitations. Social needs might have been underreported, especially among LEP patients with societal and legal concerns. Individual social needs are being documented as yes/no responses; "no" to each social need question can be due to a lack of social need or a missing response. Therefore, the actual prevalence of social needs may be higher than documented in the electronic health record. We also identified LEP based on their preferred language, which can result in identifying patients who are fluent in English and non-English language to be labeled as LEP patients.

\section{Abbreviations}

SDH: Social determinants of health; LEP: Limited English proficiency.

\section{Supplementary Information}

The online version contains supplementary material available at https://doi. org/10.1186/s13104-021-05720-7.
Additional file 1: Table S1. Social determinants of health screening questions.

\section{Acknowledgements}

We thank Khadeja Kausar, Simita Mishra, Yulia Kogan, Sabina Zak, Michael Oppenheim, and Yuval Romm for their support.

\section{Authors' contributions}

EJK: funding, concept and design, data acquisition, analysis and interpretation of data, drafting and editing of the manuscript; AF: drafting and editing of the manuscript; SA: data acquisition, drafting and editing of the manuscript; JC: concept and design, drafting and editing of the manuscript. All authors read and approved the final manuscript.

\section{Funding}

The research of Dr. Kim is supported in part by Northwell Health Research Career Development Program Award.

\section{Availability of data and materials}

The data sets used and/or analyzed during the current study are available from the corresponding author upon request.

\section{Declarations}

Ethics approval and consent to participate

The study was approved by the Northwell Health Institutional Review Board. Because the study uses deidentified, retrospective patient data, informal consent was not obtained.

\section{Consent to publish}

Not applicable.

\section{Competing interests}

The authors declare that they have no competing interests.

\section{Author details}

${ }^{1}$ Department of Medicine, Donald and Barbara Zucker School of Medicine at Hofstra/Northwell, 500 Hofstra Blvd, Hempstead, NY 11549, USA. ${ }^{2}$ Institute of Health Innovations and Outcomes Research, Feinstein Institutes for Medical 
Research, 600 Community Drive Suite 403, Manhasset, NY 11030, USA. ${ }^{3}$ Northwell Health, 5 Dakota Dr, New Hyde Park, NY 11042, USA.

Received: 23 January 2021 Accepted: 29 July 2021

Published online: 05 August 2021

\section{References}

1. Thornton RL, Glover CM, Cene CW, Glik DC, Henderson JA, Williams DR. Evaluating strategies for reducing health disparities by addressing the social determinants of health. Health Aff. 2016;35(8):1416-23.

2. Turner A. The business case for racial equity: a strategy for growth. Battle Creek: WK Kellogg Foundation; 2018.

3. Braveman P, Gottlieb L. The social determinants of health: it's time to consider the causes of the causes. Public Health Rep. 2014;129(Suppl 2):19-31.

4. McMullen AM, Katz MH. Targeting unmet social needs-next steps toward improving chronic disease management. JAMA Intern Med. 2017;177(2):252-3.

5. Sentell T, Braun KL. Low health literacy, limited English proficiency, and health status in Asians, Latinos, and other racial/ethnic groups in California. J Health Commun. 2012;17(Suppl 3):82-99.

6. Zong J, Batalova J. The limited English proficient population in the United States. Washington DC: Migration policy institute; 2015.

7. Kilbourne AM, Switzer G, Hyman K, Crowley-Matoka M, Fine MJ. Advancing health disparities research within the health care system: a conceptual framework. Am J Public Health. 2006;96(12):2113-21.
8. Algert SJ, Reibel M, Renvall MJ. Barriers to participation in the food stamp program among food pantry clients in Los Angeles. Am J Public Health. 2006;96(5):807-9.

9. Emengo VN, Williams MS, Odusanya R, et al. Qualitative program evaluation of social determinants of health screening and referral program. PLoS ONE. 2020;15(12):e0242964.

10. Tung EL, Abramsohn EM, Boyd K, et al. Impact of a low-intensity resource referral intervention on patients' knowledge, beliefs, and use of community resources: results from the communityRx trial. J Gen Intern Med. 2020;35(3):815-23.

11. Uwemedimo OT, May H. Disparities in utilization of social determinants of health referrals among children in immigrant families. Front Pediatr. 2018;6:207.

12. Buitron de la Vega P, Losi S, Sprague Martinez L, et al. Implementing an EHR-based screening and referral system to address social determinants of health in primary care. Med Care. 2019;57(Suppl 2):S133-9.

13. Abramsohn EM, Jerome J, Paradise K, Kostas T, Spacht WA, Lindau ST. Community resource referral needs among African American dementia caregivers in an urban community: a qualitative study. BMC Geriatr. 2019;19(1):311.

14. Lindholm M, Hargraves JL, Ferguson WJ, Reed G. Professional language interpretation and inpatient length of stay and readmission rates. J Gen Intern Med. 2012;27(10):1294-9.

\section{Publisher's Note}

Springer Nature remains neutral with regard to jurisdictional claims in published maps and institutional affiliations.
Ready to submit your research? Choose BMC and benefit from:

- fast, convenient online submission

- thorough peer review by experienced researchers in your field

- rapid publication on acceptance

- support for research data, including large and complex data types

- gold Open Access which fosters wider collaboration and increased citations

- maximum visibility for your research: over 100M website views per year

At BMC, research is always in progress.

Learn more biomedcentral.com/submissions 